Jurnal IImiahManajemenUbhara

\title{
PENGARUH BUDAYA ORGANISASI DAN DISIPLIN TERHADAP MOTIVASI KERJA 14 STAFF ADMIN PT MANDARIN EXPERT
}

\author{
Jeanne Liwan Pangkey ${ }^{1}$; Tungga Buana Irfana² Koesparmono Irsan3 \\ Program Studi Magister Manajemen Fakultas Ekonomi Universitas Bhayangkara Jakarta \\ Raya $^{1,2,3}$ \\ Jeane.l.pangkey@yahoo.com ${ }^{1}$; irfanatungga@gmail.com²; koesparmono.irsan@yahoo.com³
}

\begin{abstract}
ABSTRAK
Tujuan yang ingin dicapai dengan diadakannya penelitian ini adalah untuk mengetahui pengaruh budaya organisasi dan disiplin terhadap motivasi kerja staf administrasi di PT. MANDARIN EXPERT. Penelitian dilakukan di PT. MANDARIN EXPERT dengan jumlah sampel sebanyak 55 orang pegawai. Data penelitian selanjutnya dianalisis dengan menggunakan uji validitas, uji reliabilitas, uji normalitas, uji multikolinearitas, uji autokorelasi, uji heteroskedastisitas, dan pengujian hipotesis dengan uji $\mathrm{F}$ dan uji t serta analisis regresi linier sederhana dan berganda. Hasil penelitian menunjukkan bahwa budaya organisasi berpengaruh positif dan signifikan terhadap motivasi kerja staf admin PT Mandarin Expert sesuai dengan t hitung $(4,930)$ lebih besar dari t tabel $(2,000)$. Disiplin berpengaruh positif dan signifikan terhadap motivasi kerja staf admin PT Mandarin Expert sesuai dengan t hitung $(9,806)$ lebih besar dari t tabel $(2,000)$. Budaya organisasi dan disiplin secara bersama-sama berpengaruh positif dan signifikan terhadap motivasi kerja staf admin PT Mandarin Expert sesuai dengan F hitung $(295,818)$ lebih besar dari $\mathrm{F}$ tabel $(4,02)$.
\end{abstract}

\section{Kata Kunci: Budaya Organisasi, Disiplin Kerja, Motivasi Kerja. \\ THE INFLUENCE OF ORGANIZATIONAL AND DISCIPLINE CULTURE ON THE WORK MOTIVATION OF ADMIN STAFF PT MANDARIN EXPERT}

\begin{abstract}
The purpose of this research is to find out the influence of organizational culture and discipline on the motivation of administrative staff at PT. MANDARINEXPERT. Research conducted at PT. MANDARIN EXPERT with a total sample of 55 employees. The data were then analyzed by using validity test, reliability test, normality test, multicolinearity test, autocorrelation test, heteroscedasticity test, hypothesis testing with $F$ test and $t$ test, multiple and simply linear regression. The results showed that organizational culture has a positive and significant effect on work motivation of PT Excel Expert admin staff in accordance with $t$ value $(4,930)$ is higher than t table (2,0oo). Discipline has a positive and significant effect on work motivation of PT Mandarin Expert admin staff according to $t$ value $(9,806)$ is higher than t table $(2,000)$. Organizational culture and discipline together positively and significantly influence the motivation of PT Excel Expert admin staff according to F value $(295,818)$ is higher than F table $(4,02)$.
\end{abstract}

Keywords: Organizational Culture, Work Discipline, Work Motivation. 


\section{PENDAHULUAN}

Dari 4 besar sekolah Mandarin di Jakarta -Mandarin Expert, Cerdas Bangsa, BLCI, Chinalink- Mandarin Expert adalah yang terbesar dengan 8 cabang dan lebih dari 3.000 murid aktif dan telah mengirim ribuan pelajar dan mahasiswa Indonesia ke China untuk belajar formal (SMP, SMA, S1 dan S2) maupun non formal (belajar Bahasa Mandarin atau kejuruan lainnya).

PT Mandarin Expert dibentuk atas sebuah tujuan untuk menjawab tantangan globalisasi yang menjadikan kemampuan berbahasa Mandarin sebagai salah satu syarat utama dalam meningkatkan kompetensi diri. Namun persaingan yang semakin sengit dan terbuka memaksa PT Mandarin Expert untuk lebih aktif meningkatkan kemampuan dan kualitas sumber dayanya.

Sumber daya manusia yang berkualitas baik merupakan sumber daya yang terpenting dalam mencapai tujuan organisasi. Hal ini dikarenakan sumber daya manusia memiliki peranan penting sebagai penentu kebijakan operasional dan pelaksana kegiatan dalam organisasi, perusahaan, badan ataupun sejenisnya. Oleh karena itu dapat dikatakan bahwa keberhasilan atau tidaknya suatu organisasi amat tergantung pada kualitas sumber daya manusia dalam organisasi itu.

Motivasi kerja karyawan dapat dipengaruhi oleh beberapa faktor, diantaranya budaya organisasi, disiplin, kompensasi, kepemimpinan, perencanaan karir, suasana kerja, dan lain sebagainya. Motivasi kerja pada pegawai juga dapat dipengaruhi oleh disiplin. Disiplin kerja adalah ketaatan karyawan untuk bekerja sesuai dengan aturan-aturan organisasi. Disiplin menciptakan iklim kerja yang kondusif yang akan meningkatkan motivasi kerja karyawan untuk mencapai tujuan organisasi.
Dengan persaingan usaha di bidang bahasa mandarin yang kian ketat dewasa ini menuntut adanya motivasi karyawan di semua level. Motivasi kerja yang kuat tentu sangat bergantung pada komitmen manajemen puncak untuk mengatur pola kerja dan kebiasaan kerja dalam perusahaan, agar para karyawan sebagai sumberdaya perusahaan, mampu bekerja dengan disiplin dan berpedoman pada tata aturan serta nilai-nilai budaya organisasi yang telah tertanam dalam perusahaan. Dengan melihat kemajemukan karyawan serta tantangan kerja yang serba berkembang, maka perlu adanya upaya yang lebih keras dari pimpinan PT. Mandarin Expert dalam membentuk motivasi kerja yang baik.

Untuk pencapaian target/goal perusahaan seperti yang direncanakan dari awal untuk menjadi perusahaan pendidikan bahasa Mandarin terbaik dan terbesar di Indonesia, maka berbagai upaya telah dilakukan oleh PT. Mandarin Expert untuk memotivasi pegawai dalam bekerja. Beberapa diantaranya yang dilakukan perusahaan adalah dengan memberikan penghargaan bagi karyawan berprestasi, memberikan kesempatan pegawai untuk mengembangkan karir, memberikan rasa aman dalam bekerja, mendorong kedisiplinan, memperbaiki budaya organisasi, menempatkan pimpinan yang disukai pegawai, dan lain-lain.

Penguatan budaya organisasi juga telah diupayakan dengan peningkatan kualitas tampilan cabang seperti interior bergaya oriental, penggunaan cat yang berwarna kuning dan merah, penyampaian salam dalam bahasa Mandarin bagi seluruh tamu. Meskipun berbagai upaya meningkatkan motivasi pegawai telah dilakukan oleh PT. Mandarin Expert, namun masih ada saja permasalahan motivasi pegawai dimana sebagian pegawai masih ada yang terkesan kurang energik, memberikan pelayanan yang kurang berkualitas, tidak tergerak untuk mengembangkan diri, kurang bergairah dalam bekerja, tidak terdorong untuk 
memberikan kemampuan terbaiknya, dan lainlain.

Data empiris di atas menguatkan adanya permasalahan motivasi. Permasalahan motivasi yang utama terlihat pada kurangnya upaya mempengaruhi orang lain, kemauan mengenal peserta didik, semangat datang ke tempat kerja, dan semangat mengikuti tugas pelatihan. Permasalahan motivasi bersumber dari banyak faktor diantaranya insentif, penghargaan, kompensasi, kedisiplinan, budaya organisasi, kepemimpinan, iklim kerja, pengembangan karir, dll.

Berdasar observarsi, dari banyak faktor yang berpotensi menyebabkan permasalahan motivasi, terdapat dua faktor yang potensinya paling dominan yaitu budaya organisasi dan disiplin. Budaya organisasi menjadi faktor yang penting mengingat penerimaan pegawai yang tinggi atas budaya organisasi yang ditandai dengan banyaknya kesesuaian antara nilai bagi pegawai dan nilai yang dianut organisasi akan membuat pegawai lebih bersemangat dalam bekerja. Demikian pula tindakan pendisiplinan yang lebih tegas dan konsisten akan membuat pegawai tergerak untuk melakukan tugasnya.

Berdasarkan data karyawan PT Mandarin Expert pada tahun 2013 - 2017 terdapat kenaikan jumlah karyawan dari 81 karyawan menjadi 120 karyawan dengan peningkatan sebesar $37,04 \%$ per 4 tahun ( 9.35\% per tahun). Kenaikan jumlah karyawan tersebut disebabkan karena adanya penambahan cabang baru, peningkatan jumlah siswa, penambahan ruangan kelas, peningkatan biaya perawatan dan pemeliharaan dan penambahan biaya kursus.

\section{KAJIAN TEORETIK}

\section{Motivasi Kerja}

Menurut National Press Publication (2001:14), motivasi adalah suatu dorongan untuk bekerja dengan baik, berhasil, memuaskan dan tampil dengan baik. Motivasi penting bagi suksesnya pekerjaan. Perilaku seseorang adalah hasil dari beberapa faktor atau motif. Selanjutnya Robbins dan Judge (2009:209) "motivation as the processes that account for an individual's intensity, direction, and persistence of effort toward attaining goals" menyatakan bahwa motivasi adalah proses yang menyebabkan intensitas, arah dan ketekunan usaha seorang karyawan dalam mencapai tujuan.

Definisi motivasi yang dinyatakan oleh McShane dan Von Glinow (2005:72) yaitu "Motivation refers to the forces within a person that affect the direction, intensity, and persistence of voluntary behavior" dimana motivasi mengacu pada kekuatan di dalam seseorang yang mempengaruhi arah, intensitas, dan ketekunan perilaku sukarela. Pendapat McShane senada dengan pendapat Gibson (2009:129) dan kawan-kawan, yang menyatakan bahwa : "Motivation has to do with (1) the direction of behavior, (2) the strength of the response once an employee chooses to follow a course of action, and (3) the persistence of the behavior, or how long the person continues to behave in a particular manner." yang berarti motivasi harus dilakukan dengan (1) arah perilaku, (2) kekuatan respon setelah seorang karyawan memilih untuk mengikuti tindakan, dan (3) keberlangsungan perilaku atau berapa lama orang itu terus berperilaku dengan cara tertentu.

Motivasi menurut Greenberg dan Baron (2008:48) adalah: "The set of processes that arouse, direct and maintain human behavior towarrd attaining some goal." yaitu serangkaian proses yang membangkitkan, mengarahkan dan memelihara perilaku manusia ke arah pencapaian tujuan. Selanjutnya, Kinicki dan Kreitner (2008:178) berpendapat bahwa: "Motivation represents those psychological processes that cause the arousal, direction and persistence of voluntary actions that are goal directed." yaitu motivasi merupakan proses-proses psikologis yang menyebabkan gairah, arah dan ketekunan dari tindakan sukarela yang diarahkan tujuan.

Sedangkan Colquitt dan kawan-kawan (2009:178) menyatakan bahwa: "motivation is defined as a set of energetic forces that 
originates both within and outside an employee, initiates work-related effort, and determines its direction, intensity and persistence." Motivasi didefinisikan sebagai satu set kekuatan energik yang berasal baik di dalam dan di luar karyawan, memulai usaha yang berhubungan dengan pekerjaan, dan menentukan arah, intensitas dan ketekunan pekerjaan tersebut.

Menurut Michael Hitt (2012:241), motivation is a set of forces that energize, direct, and sustain behavior. Artinya Motivasi adalah seperangkat kekuatan yang memberikan energi, langsung, dan mempertahankan perilaku.

Selain hal tersebut diatas, ada pendapat Steiner on Motivation yang mengemukakan bahwa "Humans are able to work on the ground on intrinsic motivation". Dapat dikatakan bahwa manusia mampu bekerja atas dasar sesuatu dorongan yang ada dalam dirinya. Motivasi merupakan kesediaan untuk mengeluarkan tingkat upaya yang tinggi untuk tujuan organisasi, yang dikondisikan oleh kemampuan upaya itu dalam memenuhi beberapa kebutuhan individual.

\section{Budaya Organisasi}

Menurut McShane, Steve. L. \& Von Glinov, Marry Ann (2005:208) Dimensi Budaya Organisasi adalah :

a. Dimensi Budaya Pengendalian

Budaya ini menilai peran eksekutif senior untuk memimpin organisasi. Tujuannya adalah untuk mempertahankan semua orang berjalan searah dan dibawah kendali.

b. Dimensi Budaya Kinerja

Budaya ini menilai kinerja individu dan organisasi dan berusaha untuk mencapai efektivitas dan efesiensi.

c. Dimensi Budaya Hubungan

Budaya ini menilai sifat pengasuhan dan kemanusiaan. Ini mempertimbangkan komunikasi terbuka, keadilan, kerja tim, dan pembagian bagian-bagian penting dalam kehidupan organisasi. d. Dimensi Budaya Responsive

Budaya ini menilai kemampuannya untuk menyesuaikan diri dengan lingkungan eksternal, termasuk kompetitif dan merealisasikan kesempatan baru.

Menurut Richard L. Daft (2007:107) budaya dapat dianalisis pada tiga tingkat, yaitu :

a. Artifak (pakaian, pola perilaku, simbol fisik, upacara organisasi, tata letak kantor), yaitu : semua hal yang dapat dilihat, didengar dan diamati seseorang dan penglihatan para anggota organisasi.

b. Nilai-nilai

Dilihat dari cara orang menjelaskan dan membenarkan apa yang mereka perbuat dapat diinterpretasikan dari kisah-kisah, bahasa dan symbol organisasi yang dapat digunakan para anggota untuk menggambarkan mereka.

c. Asumsi-asumsi dasar dan keyakinan

Merupakan inti dari budaya dan secara dibawah sadar membimbing perilaku dan keputusan.

Menurut Stephen P. Robbins(2002:283) budaya organisasi mempunyai fungsi sebagai berikut :

a. Menentukan peran membedakan antara perusahaan satu dengan yang lain.

b. Menentukan tujuan bersama lebih dari sekedar kesenangan individu.

c. Menjaga stabilitas perusahaan.

d. Membuat identitas bagi anggota organisasi.

Menurut Stephen P. Robbins (2002:291) budaya organisasi terbentuk karena adanya:

a. Stories, yaitu cerita turun temurun tentang perusahaan, peraturan perusahaan dan reaksi terhadap kesalahan yang pernah dilakukan perusahaan tersebut.

b. Ritual , yaitu kebiasaan-kebiasaan yang dilakukan untuk mencapai tujuan.

c. Material Simbol, yaitu barang-barang yang digunakan untuk melakukan kegiatan perusahaan.

d. Language, dimana setiap kelompok biasanya memiliki bahasa khusus yang hanya dimengerti oleh setiap kelompok tersebut. 


\section{Disiplin}

Terdapat tiga tipe kedisiplinan sebagai berikut:

1. Disiplin Preventif

Menurut T. Hani Handoko (2012:209). Disiplin preventif adalah kegiatan yang dilaksanakan untuk mendorong para karyawan (pegawai) agar mengikuti berbagai standar dan aturan, sehingga penyelewengan-penyelewengan dapat dicegah. Disiplin prefentif adalah upaya yang dilakukan organisasi untuk menciptakaan keadaan dimana anggota organisasi memiliki kemauan sendiri untuk mematuhi peraturanperaturan yang telah ditetapkan. Menurut Certo (2013:333), "discipline, taken by the supervisior to prevent employees from breaking rules." Disiplin, diambil oleh supervisior untuk mencegah karyawan melanggar peraturan.

\section{Disiplin Korektif}

Prabu Mangkunegara (2004:129), mengemukakan bahwa disiplin korektif adalah suatu upaya untuk menggerakan pegawai dalam menyatukan suatu peraturan dan mengarahkan untuk tetap mematuhi peraturan sesuai dengan pedoman yang berlaku dalam perusahaan. Disiplin Korektif adalah tindakan yang dilakukan organisasi terhadap pelanggaran atas aturan-aturan yang berlaku dan mencegah terjadinya pelanggaran serupa di kemudian hari. Menurut Schermerhorn (2010:470) "Discipline is the act of influence behaviour through reprimand". Disiplin adalah tindakan mempengaruhi perilaku melalui teguran (aturan). Penegakan disiplin perlu disertai ancaman sanksi atau hukuman agar dapat memberikan dorongan untuk mentaati dan mematuhinya. Tanpa ancaman, sanksi atau hukuman, dorongan ketaatan dan kepatuhan dapat menjadi lemah serta motivasi untuk mengikuti aturan yang berlaku menjadi kurang.

3. Disiplin Progresif

Kedisiplinan dalam bekerja dapat tumbuh disebabkan rangsangan dari dalam diri setiap pegawai sebagai bentuk kesadaran penuh dan tanggung jawab terhadap profesionalisme pekerjaanya. Selanjutnya, disiplin kerja juga dapat tumbuh disebabkan karena adanya ketaatan dalam menjalankan peraturan yang mengikat. Apabila peraturan tersebut dilanggar, maka pegawai akan menerima konsekuensi dari pelanggaran tersebut dengan tujuan agar pelanggaran yang serupa tidak terulang dikemudian hari. namun demikian, jika pegawai melakukan pekerjaannya sesuai peraturan akan diganjar dengan penghargaan (reward). Menurut Mathis (2011:528), "discipline form of training that enforces organizational rules." Disiplin adalah bentuk pelatihan yang memberlakukan aturan-aturan organisasi.

Oleh karena itu, dalam membangun disiplin kerja sedikitnya diperlukan peraturan yang mengikat di mana peraturan tersebut telah disepakati sebelumnya atau telah ditetapkan sebelumnya baik melalui perangkat perundangan maupun perangkat evaluasi kinerja yang dalam hal ini menyangkut bidang kepegawaian. Selain itu, diperlukan kepekaan moral, kebiasaan-kebiasaan yang baik, dan berkelanjutan sejak dini untuk menghasilkan suatu sikap-sikap positif dan membangun di dalam diri.

Menurut Decenzo dan Robbins (2005:478), "discipline $A$ condition in the organization when employees conduct themselves in accordance with the organization's rules and standards of acceptable behavior." Disiplin adalah sebuah kondisi dalam organisasi ketika karyawan berperilaku sesuai dengan aturan organisasi dan standar perilaku yang dapat diterima. Disiplin pada dasarnya merupakan penguatan peraturan secara simultan dan memotivasi pelanggar untuk memahami peraturan-peraturan di masa datang.

\section{Kerangka Berpikir dan Hipotesis}




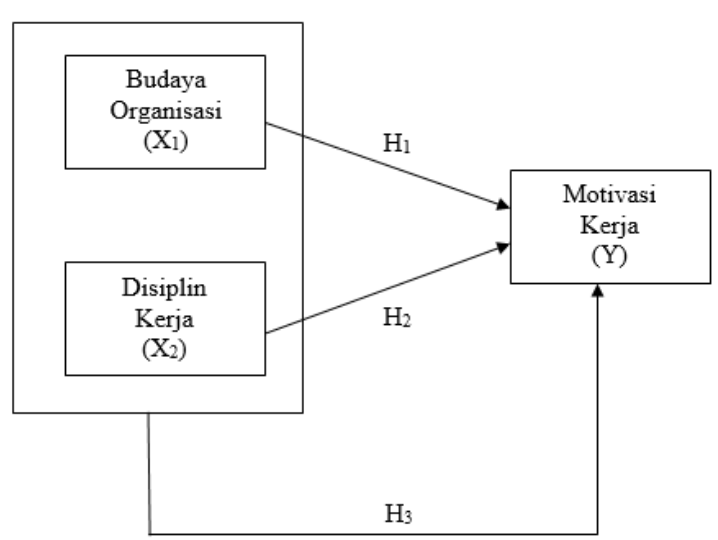

Gambar 1.

Kerangka Berpikir

\section{Metode Penelitian}

Metode penelitian dalam penelitian ini adalah metode penelitian kuantitatif dengan analisis uji $\mathrm{t}, \mathrm{F}$ dan multiple linear regression. Teknik pengumpulan data yang digunakan dalam penelitian ini adalah dengan metode survei. Pengumpulan data dilakukan dengan menggunakan kuesioner. Teknik sampling dalam penelitian ini menggunakan teknik random sampling. Populasi dan sample adalah karyawan perusahaan.

\section{HASIL PENELITIAN PEMBAHASAN}

Tabel 1.

Jenis Kelamin Responden

\begin{tabular}{|ll|r|r|r|r|}
\hline & & Frequency & Percent & Valid Percent & $\begin{array}{c}\text { Cumulative } \\
\text { Percent }\end{array}$ \\
\hline Valid & LAKI LAKI & 13 & 23.6 & 23.6 & 23.6 \\
& PEREMPUAN & 42 & 76.4 & 76.4 & 100.0 \\
& Total & 55 & 100.0 & 100.0 & \\
\hline
\end{tabular}

Sumber: Data penelitian yang diolah, 2016

Tabel 2.

Tingkat Pendidikan Responden

\begin{tabular}{|ll|r|r|r|r|}
\hline & & Frequency & Percent & Valid Percent & \multicolumn{1}{c|}{$\begin{array}{c}\text { Pumulative } \\
\text { Percent }\end{array}$} \\
\hline Valid & SMP & 3 & 5.5 & 5.5 & 5.5 \\
& SMA & 42 & 76.4 & 76.4 & 81.8 \\
& S1 & 10 & 18.2 & 18.2 & 100.0 \\
& Total & 55 & 100.0 & 100.0 & \\
\hline
\end{tabular}

Sumber: Data penelitian yang diolah, 2016
Tabel 3.

Usia Responden

\begin{tabular}{|ll|r|r|r|r|}
\hline & & & & & Cumulative \\
Prequency & Percent & Valid Percent & Percent \\
\hline Valid & $20-30$ tahun & 52 & 94.5 & 94.5 & 94.5 \\
& $31-40$ tahun & 3 & 5.5 & 5.5 & 100.0 \\
& Total & 55 & 100.0 & 100.0 & \\
\hline
\end{tabular}

Sumber: Data penelitian yang diolah, 2016

Berdasarkan hasil penelitian dengan menggunakan software SPSS versi 20 menunjukkan bahwa uji validitas dari masing-masing variabel untuk seluruh item budaya organisasi, disiplin dan motivasi adalah valid karena $r$ hitung $>r$ tabel $(0,3)$.

Berdasarkan hasil penelitian dengan menggunakan software SPSS versi 20 menunjukkan bahwa uji relibilitas untuk masing-masing variabel budaya organisasi, disiplin dan motivasi adalah reliabel karena nilai cronbach's alpha $>0.6$.

Tabel 4.

Uji Reliabilitas

\begin{tabular}{|c|c|c|}
\hline $\begin{array}{c}\text { Budaya } \\
\text { Organisasi }\end{array}$ & Disiplin & Motivasi \\
\hline 0.981 & 0.984 & 0.986 \\
\hline
\end{tabular}

Uji normalitas data variabel budaya organisasi, disiplin dan motivasi dengan uji Kolmogorov-Smirnov, menghasilkan nilai Kolmogorov-Smirnov Z adalah 0,955; 0.823 dan 0,943 dengan probabilitas Asymp. Sig. = 0,$321 ; 0.507$ dan 0,336. Karena probabilitas lebih besar daripada taraf uji penelitian (Asymp. Sig. > atau 0,321 > 0,05), maka variabel budaya organisasi, disiplin dan motivasi adalah berdistribusi secara normal.

Tabel 5

Koefisien Pengaruh Budaya Organisasi dan Disiplin Terhadap Motivasi

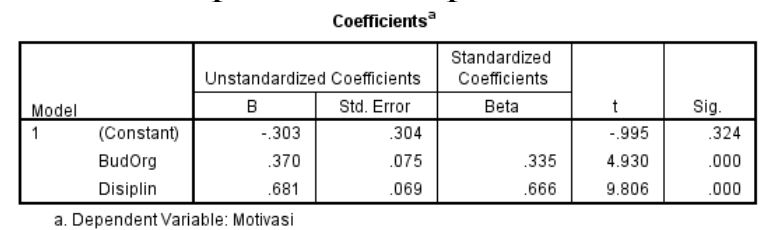


Sumber: Data penelitian yang diolah, 2016

Berdasarkan hasil penelitian menunjukkan bahwa t hitung $(4,930)$ lebih besar dari t tabel $(2,000)$ maka dapat dikatakan ada pengaruh budaya organisasi terhadap motivasi. Begitu pula t hitung $(9,806)$ lebih besar dari t tabel $(2,000)$ maka dapat dikatakan ada pengaruh disiplin terhadap motivasi

\section{Tabel 6}

Anova Pengaruh Budaya Organisasi dan Disiplin Terhadap Motivasi

\begin{tabular}{|c|c|c|c|c|c|c|}
\hline \multicolumn{7}{|c|}{ ANOVA ${ }^{a}$} \\
\hline & & $\begin{array}{l}\text { Sum of } \\
\text { Squares }\end{array}$ & df & Mean Square & $\mathrm{F}$ & Sig. \\
\hline \multirow[t]{3}{*}{1} & Regression & 39.331 & 2 & 19.666 & 295.818 & $.000^{6}$ \\
\hline & Residual & 3.457 & 52 & .066 & & \\
\hline & Total & 42.788 & 54 & & & \\
\hline
\end{tabular}

Sumber: Data penelitian yang diolah, 2016

Berdasarkan hasil penelitian menunjukkan bahwa F hitung $(295,818)$ lebih besar dari t tabel $(4,02)$ maka dapat dikatakan ada pengaruh budaya organisasi dan disiplin secara bersama-sama terhadap motivasi.

Model persamaan regresi linier ganda hasil penelitian adalah $\hat{Y}=-0.303+0.370 X 1+$ o.681X2. Model persamaan regresi linier ganda hasil analisis tersebut dapat diartikan sebagai berikut:

a. Nilai konstanta sebesar $\mathrm{a}=-0.303$, artinya bahwa jika budaya organisasi dan disiplin tidak ada maka motivasi akan bernilai negatif.

b. Nilai koefisien regresi budaya organisasi sebesar $\mathrm{b} 1=0.370$ menunjukkan bahwa budaya organisasi berpengaruh terhadap motivasi dengan arah positif, artinya semakin baik budaya organisasi maka semakin tinggi motivasi kerja, dan sebaliknya semakin buruk budaya organisasi maka semakin rendah motivasi kerja.

c. Nilai koefisien regresi disiplin sebesar b2 = o.681 menunjukkan bahwa didiplin berpengaruh terhadap motivasi dengan arah positif, artinya semakin baik disiplin kerja maka semakin tinggi motivasi kerja, dan sebaliknya semakin buruk disiplin maka semakin rendah motivasi kerja.

Tabel 7.

Model Summary Pengaruh Budaya Organisasi dan Disiplin Terhadap Motivasi

Model Summary

\begin{tabular}{|l|c|c|c|c|}
\hline Model & $\mathrm{R}$ & R Square & $\begin{array}{c}\text { Adjusted R } \\
\text { Square }\end{array}$ & $\begin{array}{c}\text { Std. Error of } \\
\text { the Estimate }\end{array}$ \\
\hline 1 & $.959^{\mathrm{a}}$ & .919 & .916 & .25783 \\
\hline
\end{tabular}
a. Predictors: (Constant), Disiplin, BudOrg
b. Dependent Variable: Motivasi

Sumber: Data penelitian yang diolah, 2016

Dari tabel tersebut diatas diperoleh nilai koefisien determinasi ganda yang disesuaikan (Adjusted R Square) sebesar 0.916. Nilai Adj. $\mathrm{R}^{2}=0.916$ menunjukkan bahwa budaya organisasi dan disiplin dalam model secara bersama-sama mampu menjelaskan $91.6 \%$ variasi $\mathrm{Y}$ sedangkan 8.4\% variasi $\mathrm{Y}$ lainnya dijelaskan oleh variabel lain yang tidak diteliti.

\section{Pengaruh Budaya Organisasi terhadap Motivasi Kerja Staf Admin PT. Mandarin Expert}

Budaya organisasi memiliki pengaruh signifikan terhadap motivasi kerja dengan arah positif , artinya makin tinggi budaya organisasi yang dirasakan staf admin di PT. Mandarin Expert maka makin tinggi pula motivasi kerja mereka. Pengaruh budaya organisasi terhadap motivasi kerja ditunjukkan oleh nilai koefisien regresi budaya organisasi sebesar b1 $=0,370$ pada model persamaan regresi linier sederhana $\hat{\mathrm{Y}}=-0.303+0.370 \mathrm{X} 1$.

Hasil penelitian ini sejalan dengan teori maupun temuan penelitian yang dilakukan oleh H. Teman Koesmono (2005), Fikri (2008), Andhatu Achsa (2011), Nur Octaviana (2011), dan Nila Tania (2013) menyimpulkan bahwa budaya organisasi berpengaruh terhadap motivasi kerja. Oleh karena itu untuk mendapatkan motivasi kerja staf admin yang semakin tinggi maka dapat diupayakan dengan menerapkan budaya organisasi yang sesuai dengan nilai, keyakinan, kebiasaan, norma, 
serta cara berpikir dan bertindak yang diterima oleh semua anggota organisasi. Penerapan budaya organisasi di PT. Mandarin Expert dapat dilakukan dengan memberikan arah dan identitas kepada staf admin agar mereka mengetahui tujuan dan pentingnya pekerjaan yang mereka lakukan untuk kemajuan organisasi, memberikan dukungan dan perhatian dari manajemen kepada staf admin, saling memberikan kontrol, integrasi, kerjasama, toleransi terhadap konflik, dan pola komunikasi yang baik antara manajemen dan staf.

\section{Pengaruh Disiplin terhadap Motivasi Kerja Staf Admin PT. Mandarin Expert}

Disiplin memiliki pengaruh signifikan terhadap motivasi kerja dengan arah positif, artinya makin tinggi disiplin yang dilakukan staf admin di PT. Mandarin Expert maka makin tinggi pula motivasi kerja mereka. Pengaruh disiplin terhadap motivasi kerja ditunjukkan oleh nilai koefisien regresi disiplin sebesar b2 = o,681 pada model persamaan regresi linier sederhana $\hat{\mathrm{Y}}=-0.303+0.681 \mathrm{X} 2$.

Hasil penelitian ini sejalan dengan teori maupun temuan penelitian yang dilakukan oleh Utin Wigiatri dan Endang Hendrayanti (2007), Siti Hidayah, Kukuh Pribadi (2011), Dannie Gunawan, Mukhlis Yunus, Amri (2013), Dian Fawzia Scubania, Saur M. Tampubolon, Sumardi (2014), Yuyun Nurhidayati (2014), Maria Ulfa dan Misbahuddin Azzuhri (2016) yang menyatakan bahwa disiplin berpengaruh terhadap motivasi kerja. Oleh karena itu untuk mendapatkan motivasi kerja staf admin yang semakin tinggi, dapat diupayakan dengan menerapkan disiplin kerja yang dapat mempengaruhi dan memperbaiki perilaku staf admin di PT. Mandarin Expert. Penerapan disiplin di PT. Mandarin Expert dapat dilakukan dengan menerapkan peraturan yang dapat ditaati, tepat waktu dalam kehadiran, tepat waktu dalam menyelesaikan pekerjaan, dapat melaksanakan tugas dengan baik dan sesuai peraturan kerja, tidak suka menunda pekerjaan, mengikuti petunjuk yang diberikan, memiliki standar perilaku yang dapat diterima, sopan dan tertib.

\section{Pengaruh Budaya Organisasi dan Disiplin Secara Bersama-sama terhadap Motivasi Kerja Staf Admin PT. Mandarin Expert}

Budaya organisasi dan disiplin memiliki pengaruh signifikan terhadap motivasi kerja, artinya terdapat pengaruh simultan budaya organisasi dan disiplin terhadap motivasi kerja staf admin di PT. Mandarin Expert. Pengaruh budaya organisasi dan disiplin terhadap motivasi kerja ditunjukkan oleh oleh nilai Adjusted R Square $=0,916$. Nilai Adjusted R Square tersebut memiliki arti bahwa 91,6\% variasi pada motivasi kerja staf admin secara bersama-sama dipengaruhi oleh budaya organisasi dan disiplin, sedangkan 8,4\% sisanya dipengaruhi oleh variable lain yang tidak diteliti.

Temuan penelitian ini menunjukkan bahwa budaya organisasi dan disiplin mempengaruhi motivasi kerja staf admin di PT. Mandarin Expert. Oleh karena itu, perlu upaya meningkatkan budaya organisasi dan disiplin secara bersama-sama. Upaya tersebut dapat dilakukan dengan jalan memperbaiki setiap variable yang berpotensi mempengaruhi motivasi kerja staf admin khususnya disiplin di PT. Mandarin Expert. Upaya peningkatan secara bersama-sama. Hendaknya diprioritaskan pada peningkatan variabel disiplin yang berdasarkan analisis regresi linier ganda pengaruhnya lebih besar daripada variable budaya organisasi.

\section{KESIMPULAN}

1. Berdasarkan hasil penelitian menunjukkan bahwa thitung $(4,930)$ lebih besar dari t tabel (2,000) maka dapat disimpulkan ada pengaruh budaya organisasi terhadap motivasi kerja staf admin di PT Mandarin Expert. 
2. Begitu pula t hitung $(9,806)$ lebih besar dari t tabel $(2,000)$ maka dapat disimpulkan ada pengaruh disiplin terhadap motivasi kerja staf admin di PT Mandarin Expert.

3. Berdasarkan hasil penelitian menunjukkan bahwa F hitung $(295,818)$ lebih besar dari t tabel $(4,02)$ maka dapat dikatakan ada pengaruh budaya organisasi dan disiplin secara bersama-sama terhadap motivasi kerja staf admin di PT Mandarin Expert.

\section{SARAN}

1. Budaya organisasi terbukti memiliki pengaruh yang signifikan terhadap motivasi kerja staf admin di PT Mandarin Expert, sehingga budaya kerja di PT. Mandarin Expert juga perlu diperkuat dan ditingkatkan yaitu dengan memperkuat keterbukaan komunikasi oleh managemen, memberikan penghargaan bagi karyawan berprestasi, memberikan kesempatan pegawai untuk mengembangkan karir, memberikan rasa aman dalam bekerja, mendorong kedisiplinan, memberikan dukungan dan perhatian bagi karyawan, menempatkan pimpinan yang disukai karyawan dan lainlain.

2. Pengaruh disiplin terhadap motivasi kerja lebih besar dibandingkan dengan pengaruh budaya organisasi terhadap motivasi kerja staf admin di PT Mandarin Expert, sehingga untuk meningkatkan motivasi kerja staf admin, diprioritaskan pada peningkatan disiplin kerja, yaitu dengan penyelesaian pekerjaan yang tepat waktu dan tepat guna (berkualitas), pelaksanaan peraturan kerja dengan baik, dan datang ke tempat kerja tepat pada waktunya.

3. Upaya peningkatan motivasi kerja staf admin di PT. Mandarin Expert hendaknya dilakukan dengan memperhatikan faktorfaktor lain yang memiki pengaruh sebesar $8,4 \%$ terhadap motivasi kerja seperti iklim dan suasana kerja, kompensasi, pengembangan karir, kepemimpinan dan lain-lain, yang tidak diteliti pada penelitian ini.

4. Organisasi dan peneliti lain diharapkan mengkaji ulang penelitian ini dengan menambahkan variabel penelitian lain, ataupun dilakukan dengan obyek penelitian yang berbeda dan unit analisis yang berlainan. Penelitian lanjutan dapat pula dilakukan dengan analisis kualitatif yang lebih mendalam.

\section{DAFTAR PUSTAKA}

A. Tolkah Mansur, 2009, “Analisis Pengaruh Budaya Organisasi dan Rotasi Pekerjaan Terhadap Motivasi Kerja untuk Meningkatkan Kinerja Pegawai Ditjen Pajak (Studi Pada Kantor Pelayanan Pajak Berbasis Administrasi Modern KPP Pratama Semarang Timur)", Tesis Program Pasca Sarjana Magister Manajemen UNDIP.

Achsa, Andhatu ,2011, Pengaruh Budaya Organisasi Terhadap Motivasi dan Kepuasan Kerja serta Kinerja Karyawan (Studi Pada SPBU di Salatiga), Tesis Program Pasca Sarjana Magister Manajemen UNDIP.

Certo, Samuel C dan S. Trevis Certo, 2013. Modern Management Concepts and skill, Pearson.

Daft, Richard L, 2007. Managemen Edisi G. PT. Salemba Empat, Jakarta.

David A. DeCenzo, Robbins, Stephen P, 2010. Fundamentals of Human Resource Management. (New Jersey, John Wiley \& Sons Inc, $10^{\text {th }}$ Edition).

Fikri, 2008, "Pengaruh Tipe Kepemimpinan dan Budaya Organisasi terhadap Motivasi Kerja Pegawai Kecamatan Lowokwaru Kota Malang”, Jurnal Aplikasi Manajemen, Volume 6, Nomor I , April 2008

Fred Luthans, 2011. Organizational Behavior, (New York: Mc Grawhill, 12 $^{\text {th }}$ Editions).

Ghozali, Imam, 2005. Aplikasi Analisis Multivariate Dengan Program SPSS, Badan Penerbit Universitas Diponegoro, Semarang.

Gibson, James L, 2009. Organizations, Behavior Structure, Process, Boston, McGraw, Hill Irwin. 
Greenberg, Jerald dan Robert A. Baron, 2008. Behavior in Organizations, Pearson Prentice Hall.

Greg L Stewart, 2011. Human Resource Management, Linking Strategy to Practice, (Danvers; John Wiley \& Sons, Inc, Second Edition).

Grund, Christian dan Sliwka, Dirk, 2001. The Inpact of Wage Increase on job Satisfaction Empiorical Evidence and theoritical implications. Iza's Research Area Mobility And Flexibility of Labor Market, Bonn, Germany, page 13-14.

Gunawan,D., Mukhlis Yunus, Amri, 2013, Pengaruh Lingkungan Organisasi, Kompensasi dan Disiplin Kerja Terhadap Motivasi Kerja serta dampaknya Terhadap Kinerja Pegawai Kantor Pertanahan Kota Banda Aceh, Jurnal Manajemen, Pascasarjana Universitas Syiah Kual, Volume 2 No. 1, November 2013, halaman 36-45.

Hair, Joseph F. JR, Anderson Rolph E, Tathan Ronald L. Black William, 1995 Multivariate Data Analysis With Reading, Prientice Hall, Internasional Edition, New Jersey.

Handoko T. Hani, 2012. Managemen, BPFE UGM, Yogyakarta.

Hasanuddin, 2011, Pengaruh Budaya Organisasi dan Kepemimpinan Terhadap Motivasi Kerja serta Dampaknya pada Kinerja Organisasi (Studi Kasus Bappeda Kabupaten Aceh Besar), Tesis Program Pascasarjana Universitas Syiah Kuala, Banda Aceh.

Hidayah, S, dan Kukuh Pribadi, 2011, Analisis Pengaruh Disiplin Kerja dan Komunikasi Kerja Terhadap Kinerja dengan Mediasi Motivasi Kerja Pegawai (Studi Kasus Pegawai Pada Dinas Kelautan Dan Perikanan Kota Semarang), Jurnal Ekonomi Manajemen Akuntansi Vol. 19 No. 31.

Hofstede, Geert, Michael Harris Bond and Chung-Leung Luk, 1993. Individual Perception of Organitational Cultures,

Jhon E. Hanke, 1992, Businness Forecasting, Fourt Edition. Allyn Bacon, Boston
Jason A. Colquitt, Jeffery A. LePine \& Michael J. Wesson, 2009. Organizational Behavior: Improving Performance and Commitment in the Workplace (New YorkL McGraw Hill,

Jerald Greenberg and Rober A. Baron, 2008. Behavior in Organizations, Ninth Edition (New Yjersey : Perason Prentice Hall)

Jhonson Ricard A, Wichern Dean W, 1992 Applied Multivariate Statistical Analysis, Prientice Hall, New Jersey.

John R. Schermerhorn, 2010. Introduction to Management. (New Jersey : John Wiley \& Sons (Asia) Pte. Ltd.)

John W. Newstrom, 2007. Organizational Behavior. Twelfth Edition (New York: McGraw-Hill Companies, Inc).

Kinicki and Kreitner, 2008. Organizational Behavior, Third Edition, (New York: McGraw-Hill Companies Inc).

Koesmono, H.T., 2005, Pengaruh Budaya Organisasi Terhadap Motivasi Dan Kepuasan Kerja Serta Kinerja Karyawan Pada Sub Sektor Industri Pengolahan Kayu Skala Menengah Di Jawa Timur, Jurnal Manajemen dan Kewirausahaan Vol. 7 No. 2, September 2005, halaman 171-188.

Kusumawati, S.D., 2014, Pengaruh Budaya Organisasi dan Motivasi Kerja Terhadap Kinerja Pegawai di Kantor Regional 1 Badan Kepegawaian Negara Yogyakarta, Skripsi Fakulta Ekonomi Universitas Negeri Yogyakarta.

Majia, Luis R Gomez, David B. Balkin, Robert L. Cardy, 2012. Managing Human Resources, Prentice Hall.

Mangkunegara, 2004. Anwar Prabu. Manajemen Sumber Daya Manusia Perusahaan, PT. Remaja Rosdakarya. Bandung

Masrukhin dan Naridin, 2006. Pengaruh Motivasi Kerja, Kepuasan Kerja, Budaya Organisasi dan Kepemimpinan Terhadap Kinerja Pegawai, Jurnal Ekonomi dan Bisnis Vol. 7 No.2. 
Mathis, Robert L, 2011. Human Resource Management Esential Perspective, South Western Language Learnig.

Montgomery Dauglass C, 1982, Inteoduction to linear Regression Analysis, John Wile \& Sons, New York.

Mullins, Laurie, 2004. Management and Organizational Behavior, Prentice Hall.

Mc. Kenna, Eugenedan Nic Beech, 1195. Essence of Human Resource Management, Paperback.

Mc.Shane, Steve L dan Mary Ann Young Von Glinov. Organizational Behavior, Thirth Edition, Mc Grow Hill, 2005.

Michael A. Hitt, 2012. Management, (New Jersey, Prentice Hall)

Moeljono, Djoko Santoso, 2003. Budaya Korporat dan Keunggulan Korporasi, Jakarta : Elex Media Komputindo.

Naresh, Maholtra, 1996, Marketing Research, Prentice Hall, London

National Press Publication, 2001. Peak Performance (Jakarta, PT Elex Media Komputindo.

Norman Draper, Smith Harry, 1992 Nalisis Regresi Terpadu, Edisi Kedua, Gramedia, Jakarta.

Nurhidayati, Y., 2014, Pengaruh Kompetensi Profesional dan Kedisiplinan Guru Terhadap Motivasi Belajar Siswa MTs An-Nawawi 02 Purwosari Kecamatan Salaman Kabupaten Magelang Tahun Pelajaran 2014/2015, Skripsi Program Studi Pendidikan Agama Islam, Sekolah Tinggi Agama Islam Negeri Salatiga.

Octaviana, Nur, 2011, Pengaruh Budaya Organisasi Terhadap Motivasi dan Kepuasan Kerja serta Kinerja Karyawan (Pada PT. Mirota Kampus di Yogyakarta), Skripsi Jurusan Manajemen Fakultas Ekonomi Universitas Pembangunan Nasional "Veteran" Yogyakarta.

Pareek, Udai, 1985. Motivational Analysis of Organisational Behavior (MAO-B),

Ranupandojo, H dan Suad Husnan, 1999. Manajemen Personalia, Yogyakarta, BPFE, Edisi Keempat.

Robbins, Stephen P, 2002. Organizational Behavior, Nineth Edition, Prentice Hall Intenational, inc .Robert L. Mathis, John
H. Jackson, Human Resource Management, (Mason: Cengage Learning, $13^{\text {th }}$ Edition, 2011).

Samuel C. Certo, Supervision, Concept and Skill-Building, (New York; McGraw Hill, Eighth Edition, 2013)

Seber G. A.E. 1984, Multavariate Observations. Jhon Willey and Sons, New Yrk.

Scubania, D.F., Saur M. Tampubolon, Sumardi, 2014, Pengaruh Disiplin Belajar Terhadap Motivasi Belajar Siswa, Skripsi Program Studi Pendidikan Guru Sekolah Dasar Fakultas Keguruan Dan Ilmu Pendidikan Universitas Pakuan. Bogor.

Stewart, Greg l dan Keneth G. Brown, 2011. Human Resaurce Magament, Second Edition, Wiley.

Steven L. McShane and Mary Ann Von Glinow, Organizational Behavior (essentials), Second Edition (New York: McGrawHill, 2009).

Tania, Nila, 2013, Pengaruh Budaya Organisasi Terhadap Motivasi Kerja Karyawan, Studi Kasus di Pondok Pesantren Moderen Islam Assalam kota Surakarta, Artikel Publikasi Ilmiah, Universitas Muhammadiyah Surakarta. 